\title{
Learning to spell as a function of trial-and-error performance or observation
}

\author{
MELVIN H. MARX and KATHLEEN MARX \\ University of Missouri, Columbia, Missouri 65201
}

\begin{abstract}
An experiment is reported in which elementary school children learned to spell very difficult words in a single practice session. Subjects learned better under performance (trial-and-error) than observation conditions. Girls were superior to boys, but only under the observation condition. A reliable interaction of individual/cooperative practice with grade was found, with fourth and fifth graders superior under cooperative and sixth graders superior under individual conditions.
\end{abstract}

This study was designed to test in a field situation some propositions concerning multiple-choice learning that have been worked out in the laboratory. The purpose was to compare two basic behavioral processes as determinants of efficiency in the learning of the spelling of very difficult words by elementary school pupils. Performing, as here defined, refers to the usual trial-and-error type of responding, with knowledge of results; observing refers to the watching of someone else's performance.

The perform/observe variable was investigated in two experiments by Hillix and Marx (1960) in which it was found that observers acquired a series of stimulus-response associations at a reliably faster rate than performers. This observer superiority was subsequently confirmed in a large number of experiments by Rosenbaum (see Rosenbaum \& Arenson, 1968), including one on elementary school children (Rosenbaum \& Schutz, 1967). More recently, using more discrete stimulus-response items, we have not been able to replicate the observer superiority so consistently, although we did find in one study (Marx \& Marx, 1970) a reliable increment in observer learning relative to performer learning over the fourth to the sixth grade. The present experiments were therefore planned primarily to determine whether pupils in the higher elementary

This research was supported in part by Research Career Award 1-K6-MH-22, 023 from the National Institute of Mental Health, to the first author, by Grant NSF-GB-8506 from the National Science Foundation, by Grant URC-726 from the University of Missouri Research Council, and by Grant DAHC19-74-G-0008 from the U.S. Army Research Institute for the Behavioral and Social Sciences. The views expressed herein are the authors' own and do not necessarily reflect those of the Department of the Army. For their cooperation we are indebted to the following personnel of the Pinellas County, Florida, public school system: Dr. Thomas Southard and his successor. Mr. Nicholas Mangin, Superintendent; Mrs. Lillian H. Laird, Principal of the Lynch Elementary School; and the following teachers: Miss Betty Privitte, Mrs. Ruth Tibbetts, Mrs. Joan McMullen, Miss Linda Wist, Miss Carol Reynolds, and Mrs. Ruth Parker. We also thank Dr. Peter Hasselriis, of the University of Missouri-Columbia, for his critical reading of the manuscript. grades would learn to spell difficult words more rapidly under one or the other of these two practice conditions.

Although the primary objective of this experiment was to determine the effect of the perform/observe variable on fourth, fifth, and sixth graders' spelling, a secondary objective was to investigate the role of social cooperation vs. individual practice in this learning situation. A much cited study by Durrell (1959) suggested that "team learning" is a more effective practice condition than the more usual individual procedure. However, as Durrell himself pointed out, "It is, of course, impossible to single out any experimental factor as the major element in the study. The results cannot be attributed to team learning alone, to pupil specialties, to discussion techniques, or to enrichment activities" $(1959$, p. 8). Cooperative work between pairs of 10 - and 12-year-old children was found to produce learning that was somewhat superior to individual efforts (Amaria, Biran, \& Leith, 1969), but the problem-solving studies reviewed by Maier (1970) yielded advantages to individuals as well as groups. Thus, there seems to be a need to determine whether or not social cooperation does in fact facilitate learning, and the present experiment represents an initial effort in this direction.

\section{METHOD}

Subjects

All of the pupils present during the training day in two classes each from the fourth, fifth, and sixth grades of an elementary school were included in the experiment. A total of 166 pupils was thus involved.

\section{Experimental Design}

One class from each grade was assigned to the individual practice (I) condition, and the other class to the cooperation (C) condition. The pupils in each class were divided into pairs, like-sexed and of approximately equivalent ability level (as judged by the teacher). Members of each pair alternated between the performer $(P)$ and the observer $(0)$ role.

\section{Stimulus Materials}

Twelve words to be learned were selected for each grade from a spelling bee pamphlet. An Eastman Ektagraphic projector was 
used to show the correct spellings of the words by means of $2 \times 2$ in. slides.

\section{Procedure}

Training. After appropriate seating arrangements and preliminary instructions, each class was given a pretest on the 12 words. Then four practice trials were administered, and a test was given to conclude the training session.

After each word was called out orally by the experimenter, and a brief definition of it given during the pretest and the first training trial, $10 \mathrm{sec}$ were allowed for the performer in each pair to attempt to spell it. At the end of the spelling period for the sixth word, the correct spellings were shown on a slide. Observers now checked the spellings, placing a check mark after each word that was spelled correctly and indicating the errors of omission or commission in faulty words, as the performer watched. Two minutes were allowed for this correction procedure. Then the two subjects in each pair exchanged roles, with the previous observer becoming the performer for the last six words in the list. The same procedure was used for these words.

To facilitate scoring and also aid in separation of the perform/observe functions, one member from each pair was assigned to the "red team" and the other to the "blue team." The major functional significance of this step was to allow use of two colored pencils, in accordance with the team color. Thus, red team members corrected blue team performance records in a clearly contrasting color, and vice versa.

The words within each set of six were presented in different (random) orders on successive trials.

During the 10-sec spelling period, IP subjects worked by themselves, while 10 members of each pair merely watched. During this period, CP subjects were encouraged to solicit aid in the spelling from their $\mathrm{CO}$ partners, as quietly as possible, and were allowed to use scratch paper to try out tentative spellings. The final decision in each case, however, was to be made by the $P$ subject.

\section{RESULTS}

\section{Perform/Observe Variable}

Although negligible differences between $P$ and $O$ scores occurred on both pretest and retest, on the test, subjects consistently made more correct responses under the $\mathbf{P}$ condition. These data are given, for the three grades separately and for all subjects combined, in Table 1.

An analysis of variance performed on the test data indicated that the $\mathrm{P} / \mathrm{O}$ variable was not reliable for Grade $4(F=3.13, p>.05$, for $1 / 47 \mathrm{df})$, while it was reliable for Grade $5(F=6.97, p<.025$, for $1 / 61 \mathrm{df})$ and Grade $6(F=6.04, p<.025$, for $1 / 55 \mathrm{df})$, as well as for all of the subjects $(F=15.22, p<.001$, for $1 / 165 \mathrm{df}){ }^{1}$

\section{Table 1}

Mean Number of Correct Words on Pretest and Test by $P$ and $O$ for Three Grades and All Subjects

\begin{tabular}{lcccccc}
\hline & & \multicolumn{5}{c}{ Number Correct } \\
\cline { 3 - 4 } \cline { 6 - 7 } Grade & $\mathrm{n}$ & $\mathrm{P}$ & $\mathrm{O}$ & & $\mathrm{P}$ & $\mathrm{O}$ \\
\hline Fourth & 48 & .54 & .50 & & 3.21 & 2.81 \\
Fifth & 62 & .35 & .26 & & 2.97 & 2.50 \\
Sixth & 56 & .07 & .20 & & 4.20 & 3.43 \\
All Subjects & 166 & .31 & .30 & & 3.45 & 2.90 \\
\hline
\end{tabular}

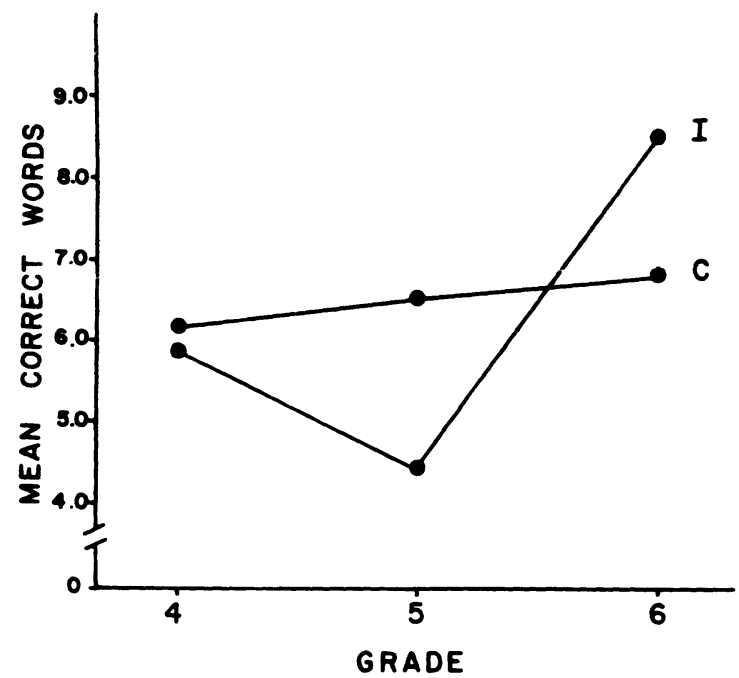

Figure 1. Mean number of correct words on test by grade and $\mathrm{C} / \mathrm{I}$ variables.

\section{Cooperation/Individual Variable}

The test data for this variable are plotted in Figure 1. The main effect of $\mathrm{C} / \mathrm{I}$ was not reliable $(\mathrm{F}<1.00)$ but, as suggested in the figure, there was a reliable interaction of $C / I$ by Grade Level $(F=4.10$, $p<.05$, for $2 / 155 \mathrm{df}$ ), which is evident as superior acquisition for the $\mathrm{C}$ condition in the fifth grade but for the I condition in the sixth grade.

\section{Other Variables: Grade Level, Sex}

As suggested in Figure 1, the main effect of Grade Level was reliable $(F=4.97, p<.01$, for $2 / 155 \mathrm{df}$ ), with a positive relationship between mean correct words and grade level except for a slight inversion in the fifth grade (means of $6.06,5.47$, and 7.63 in increasing order).

The main effect of Sex was reliable $(F=5.57$, $\mathrm{p}<.05$, for $1 / 155 \mathrm{df}$ ), with girls superior at each grade level (overall mean of 7.03 correct words compared to 5.65). In this analysis the girls clearly excelled the boys in the number of correct words they achieved as observers (3.40 to $2.38 ; F=10.14$, $\mathrm{p}<.001$ for $1 / 154 \mathrm{df}$ ), but they were only slightly, and not reliably, superior as performers (3.62 to $3.27 ; F=1.17, p>.05$ for $1 / 154 d f$ ).

\section{DISCUSSION}

The present demonstration of a statistically reliable advantage in acquisition for performance, or trial and error with reward, as opposed to observation, or a purely informative process. is consistent with results with college students recently obtained by Marx and Witter (1972). In that study subjects repeated both correct responses and errors more often from training trial to immediately following test trial when performing than when observing; the mean number of correct responses, however, did not differ, so that the present data represent something of an 
extension. They further extend the distinction between the observer superiority originally obtained by Hillix and Marx (1960) with serial multiple-choice learning material and the contrary results now being obtained with discrete-item associations.

With regard to the cooperation/individual practice variable, it seems to have been generally ineffective in the present learning situation. The one statistically reliable interaction, between $\mathrm{C} / \mathrm{I}$ condition and grade level, cannot be theoretically interpreted with any assurance until replicated. As Figure 1 indicates, the interaction is clearly attributable to the marked decrement in the I score for the fifth grade, a result which at the present time is probably best attributed to sampling variation. Whether individual practice is really superior to cooperation in the sixth grade. where there may well be an increasing emphasis on competition, also of course needs to be determined by further data; but this relationship does offer some interesting food for speculation.

The fact that girls were reliably superior at test only in the observer situation is consistent with similar trends previously noted, although typically the differences have not been quite reliable statistically. The tendency for males to excel in performance (e.g., Marx \& Witter, 1972) represents the other side of the same coin. It seems that there is a fundamental interaction of sex and performance/observation which should be checked out systematically.

\section{NOTE}

1. Owing to the wide variatiun in $N(48,62$, and 56 for the fourth, fifth, and sixth grades, respectively), separate withinsubject ANOVAs were run for each grade and for the total $\mathbf{N}$, in order to avoid severe reduction in subjects by random dropping of subjects to equalize Ns. This use of unequal-n ANOVA rendered it impossible to compute the interaction of $P / O$ with the grade variable that is suggested in Table 1 , or with either of the other intersubject variables $(\mathrm{C} / \mathrm{I}$ and sex).

\section{REFERENCES}

Amaria, R. P., Biran, L. A., \& Leith, G. O. Individual vs. cooperative learning: I. Influence of intelligence and sex. Educational Research, 1969, 11, 6-103.

Durrell, D. D. Adapting instruction to the learning needs of children in the intermediate grades: A summary. Journal of Education, 1959, 142, 2-10.

Hillix, W. A., \& Marx, M. H. Response strengthening by information and effect in human learning. Journal of Experimental Psychology, 1960, 60, 97-102.

MAIER, N. R. F. Problem solving and creativity in individuals and groups. Belmont, Calif: Brouks/Cole, 1970.

MarX, M. H., \& Marx, K. Observation vs. performance in learning over the fourth to sixth grades. Psychonomic Science, 1970, 21, 199-200.

MARX, M. H., \& WITTER, D. W. Repetition of correct responses and errors as a function of performance with reward or information. Journal of Experimental Psychology, 1972, 92, 53-58.

Rosenbaum, M. E., \& Arenson, S. J. Observational learning: Some theory, some variables, some data. In E. C. Simmel, R. A. Hoppe, \& G. A. Milton (Eds.), Social facilitation and imitative behavior. Boston: Allyn \& Bacon, 1968. Pp. 111-134.

Rosenbaum, M. E., \& Schutz, L. J. The effects of extraneous response requirements on learning by performers and úuservers. Psychonomic Science, 1967, 8, 51-52.

(Received for publication April 12, 1976.) 